\title{
Application of a Burkholderia cepacia lipase- immobilized silica monolith to batch and continuous biodiesel production with a stoichiometric mixture of methanol and crude Jatropha oil
}

\author{
Koei Kawakami, Yasuhiro Oda and Ryo Takahashi
}

\begin{abstract}
Background: The enzymatic production of biodiesel through alcoholysis of triglycerides has become more attractive because it shows potential in overcoming the drawbacks of chemical processes. In this study, we investigate the production of biodiesel from crude, non-edible Jatropha oil and methanol to characterize Burkholderia cepacia lipase immobilized in an n-butyl-substituted hydrophobic silica monolith. We also evaluate the performance of a lipase-immobilized silica monolith bioreactor in the continuous production of biodiesel.

Results: The Jatropha oil used contained 18\% free fatty acids, which is problematic in a base-catalyzed process. In the lipase-catalyzed reaction, the presence of free fatty acids made the reaction mixture homogeneous and allowed bioconversion to proceed to $90 \%$ biodiesel yield after a 12 hour reaction time. The optimal molar ratio of methanol to oil was 3.3 to 3.5 parts methanol to one part oil, with water content of $0.6 \%(\mathrm{w} / \mathrm{w})$. Further experiments revealed that $B$. cepacia lipase immobilized in hydrophobic silicates was sufficiently tolerant to methanol, and glycerol adsorbed on the support disturbed the reaction to some extent in the present reaction system. The continuous production of biodiesel was performed at steady state using a lipase-immobilized silica monolith bioreactor loaded with $1.67 \mathrm{~g}$ of lipase. The yield of $95 \%$ was reached at a flow rate of $0.6 \mathrm{~mL} / \mathrm{h}$, although the performance of the continuous bioreactor was somewhat below that predicted from the batch reactor. The bioreactor was operated successfully for almost 50 days with $80 \%$ retention of the initial yield.
\end{abstract}

Conclusions: The presence of free fatty acids originally contained in Jatropha oil improved the reaction efficiency of the biodiesel production. A combination of B. cepacia lipase and its immobilization support, $n$-butyl-substituted silica monolith, was effective in the production of biodiesel. This procedure is easily applicable to the design of a continuous flow-through bioreactor system.

\section{Background}

Production of biodiesel (fatty acid alkyl esters) through transesterification of virgin plant oils, as well as low-quality waste oils with short-chain alcohols, has received considerable attention during the past decade for producing a biodegradable and nonpolluting fuel. The conventional method for industrial biodiesel production is a chemical

\footnotetext{
* Correspondence: kawakami@chem-eng.kyushu-u.ac.jp

Department of Chemical Engineering, Faculty of Engineering, Graduate School, Kyushu University, 744 Moto-oka, Nishi-ku, Fukuoka 819-0395, Japan
}

process using acid or base catalysts [1-3]. The chemical process offers a high yield of biodiesel in a short reaction time but has drawbacks, such as the need to remove the catalyst and by-products, and high energy consumption [1-5]. As an alternative, an enzymatic process using lipase as a biocatalyst may overcome these problems because lipases can catalyze a variety of transesterification and esterification reactions relatively efficiently under mild conditions and in non-aqueous environments [1-8]. Thus considerable research has been directed at achieving high yields of biodiesel in short reaction times, for various

() Biomed Central

(c) 2011 Kawakami et al; licensee BioMed Central Ltd. This is an Open Access article distributed under the terms of the Creative Commons Attribution License (http://creativecommons.org/licenses/by/2.0), which permits unrestricted use, distribution, and reproduction in any medium, provided the original work is properly cited. 
feedstocks ranging from virgin vegetable oils to low-quality acid oils with high free fatty acid content. Among nonedible oils, Jatropha curcas, which is toxic owing to the presence of carcinogenic phorbol esters, has great potential for biodiesel production [9-13].

Immobilization of lipase is an essential technology in enabling us to perform continuous production of biodiesel using packed-bed bioreactors [14-21]. The immobilized Candida antarctica B lipase commercialized as 'Novozyme 435 ' has been investigated widely and is reported to exhibit the best performance [22-24]. However, although methanol is the most commonly used acyl acceptor, the enzyme is deactivated in the presence of small droplets of insoluble methanol $[15,22,25]$. Several strategies have been attempted to overcome this adverse effect, including stepwise addition of methanol to the reaction mixture $[15,22,26]$, use of alcohols with longer alkyl chains than methanol [24,26-30], use of methyl or ethyl acetate [23,31-33] as acyl acceptors, and the introduction of organic solvents, such as ter-butanol, that are not accessible to the lipase [18,26,34-38]. Other researchers have shown that lipases from Pseudomonas species are the most promising for biodiesel production [9,27-29,39-45]. Immobilization support materials include particles of diatomaceous earth $[9,40,42]$, polypropylene [40,42,44,45], mesoporous silica [45], kaolinite [27], and silica-polyvinyl alcohol composite [43,46].

It is now well known that lipases are highly activated and stabilized, owing to conformational change leading to the open-lid structure, when encapsulated in alkyl-substituted silicates by the sol-gel method $[47,48]$, and the resultant preparations are used effectively for many organic syntheses [49-51]. Several researchers have applied sol-gel immobilized lipases to the production of biodiesel. Hsu et al. $[16,28,30]$ prepared immobilized Burkholderia cepacia (formerly Pseudomonas cepacia) lipase in a phyllosilicate sol-gel matrix and used it for the transesterification of tallow and grease. Repeated production of ethyl esters was also performed in a recirculating packed-column bioreactor loaded with particles of immobilized lipase [16]. Noureddini et al. [41] immobilized B. cepacia lipase within a hydrophobic iso-butyl-substituted sol-gel support and succeeded in producing methyl and ethyl esters yield of $67 \%$ and 65\%, respectively, from soybean oil in 1 hour. Lipase from the same origin was also immobilized in a methylsubstituted silica aerogel and applied in the transesterification of sunflower seed oil with methyl acetate [32].

Recently, we demonstrated that a macroporous, nonshrinkable silica monolith could be formed easily from a mixture of methyltrimethoxysilane (MTMS) and tetramethoxysilane (TMOS), and that an enzyme-immobilized silica monolith was applicable as a flow-through microbioreactor for organic syntheses [52]. We also developed a highly efficient bioreactor loaded with a lipase-immobilized silica monolith by adopting a two-step sol-gel method, that is, by preparing an MTMS-based silica monolith coated with butyl-substituted silicates that entrapped lipase [53]. We applied this type of bioreactor to the continuous production of fatty acid methyl esters through methanolysis of rapeseed oil in $n$-hexane by Rhizopus oryzae lipase [54]. The use of such an enzyme-immobilized silica monolith bioreactor is expected to be useful for the biodiesel production, because it offers several benefits, including very low backpressure, high contacting efficiency and mechanical durability, as compared with conventional packed-bed bioreactors [52-54]. In the present study, we selected $B$. cepacia lipase as the most promising enzyme, and investigated the production of biodiesel through solvent-free methanolysis of Jatropha oil in batch and continuous bioreactors loaded with lipase-immobilized silica monoliths.

\section{Results and Discussion}

Batchwise production of biodiesel using a lipaseimmobilized crushed silica monolith

\section{Characterization of methanolysis of crude Jatropha oil by}

\section{lipase-immobilized silicates}

The crude Jatropha oil used was received as a kind gift from the Hak plantation, Banteay Meanchey, Cambodia. The fatty acid composition of this oil is given in Table 1. The composition of the four acids, palmitic, stearic, oleic and linoleic, was in the range of previously reported values $[12,13]$. However, the oil originally contained $18 \%$ free fatty acids, possibly owing to inappropriate handling and storage. This caused a miscible solution at a stoichiometric 3:1 molar mixture of methanol and Jatropha oil. The rapeseed oil used was fatty acid-free and did not form a miscible solution with methanol.

In this study, the molar ratio of methanol to oil was determined based on the molar amount of triglyceride that was supposed to be originally present in the feedstock. Therefore the 3:1 molar mixture meant an equimolar mixture of methanol and total fatty acids contained in the

Table 1 Fatty acid composition of the Jatropha oil

\begin{tabular}{lcl}
\hline Fatty acid & Structure & $\%(\mathbf{w} / \mathbf{w})$ \\
\hline Palmitic & $16: 0$ & 14.6 \\
Palmitoleic & $16: 1$ & 0.7 \\
Stearic & $18: 0$ & 6.9 \\
Oleic & $18: 1$ & 46.2 \\
Linoleic & $18: 2$ & 30.8 \\
Linolenic & $18: 3$ & 0.2 \\
Arachidic & $20: 0$ & 0.3 \\
Non-identified & & 0.3 \\
\hline Free fatty acids & & 18.3 \\
Monoglyceride & & 2.1 \\
Diglyceride & & 12.1 \\
Triglyceride & & 65.8 \\
\hline
\end{tabular}


feedstock. Figure 1 compares the rate of biodiesel production from different oil feedstocks. The methanol to oil molar ratio of 3:1 was selected because the production rate was highest at this molar ratio in the early stage of the conversion. The rate of methanolysis of rapeseed oil was low, probably owing to the insoluble nature of methanol in the rapeseed oil, causing direct contact between methanol droplets and lipase molecules and thereby deactivating the lipase. The methanolysis rate of crude Jatropha oil containing $18 \%$ free fatty acid was the highest among the systems investigated, and the biodiesel yield approached nearly $90 \%$ after 12 hours. In addition, the immobilized lipase gave a six-fold higher initial conversion rate as compared with its non-immobilized counterpart, being consistent with previous study $[47-51,53,54]$. The methanolysis of rapeseed oil containing $18 \%$ oleic acid was attempted to examine the effect of homogeneity of the reaction mixture. Interestingly, the reaction rate increased and exhibited similar kinetic behavior to the methanolysis of crude Jatropha oil. An additional reason for the increase in production rate may be that the rate of methyl-esterification of fatty acids is generally faster than that of the methanolysis of triglycerides [55,56]. Jachmanian et al. [20] have also reported that the addition of alkyl esters appears to be a useful tool to ensure homogeneous conditions in both substrate and product mixtures. In any case, this trend illustrates an advantage of the lipase method in the production of biodiesel, because in the alkaline method, incorporation of the free fatty acid leading to soap formation should be avoided.

\section{Effect of water content on biodiesel yield}

Water content is an important parameter in bioconversions in non-aqueous media. A small amount of water is required to maintain conformational flexibility of the lipase molecules, while excess water causes ester hydrolysis $[7,8,27,29,41,44]$. Figure 2 shows the effect of water content, ranging from $0.1 \%$ to $10 \%(\mathrm{w} / \mathrm{w})$ on the basis of total mass of reaction mixture, on the biodiesel yield in the methanolysis of Jatropha oil. The biodiesel yield at 0.5 hours increased with an increase in water content up to $1 \%$ and decreased slightly thereafter. The final yields of biodiesel at 12 hours and 24 hours were influenced less by an increase in water content up to $1 \%$, but decreased gradually with further increase in water content. This suggests that the biodiesel production proceeded at a water content up to $1 \%$ without being subjected to hydrolysis reaction. The water content of $1 \%$ $(\mathrm{w} / \mathrm{w})$ is equivalent to $0.8 \%$ reaction volume. Shah and

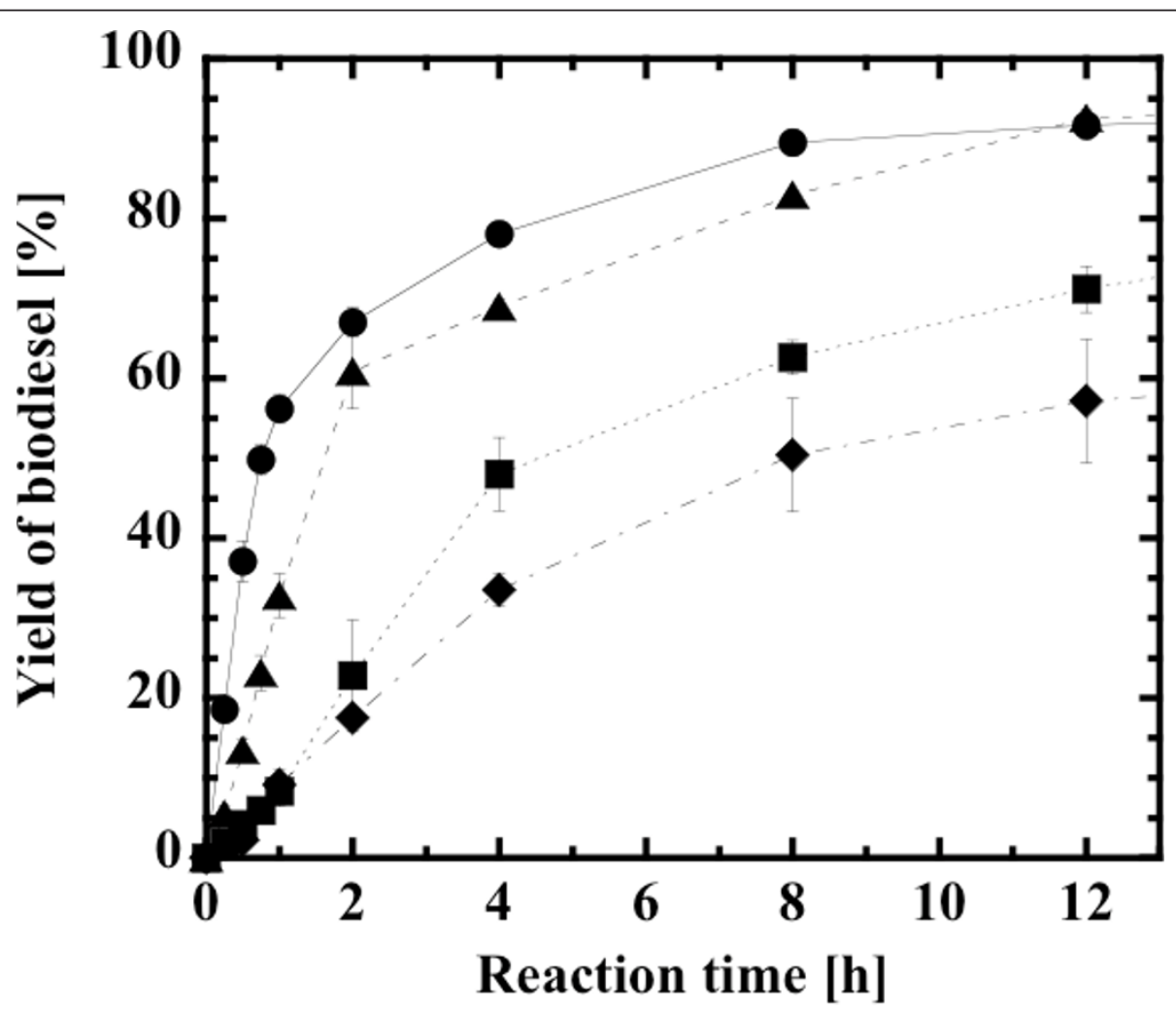

Figure 1 Comparison of the production rate of biodiesel from different oil feedstocks. Jatropha oil and methanol (closed circles), rapeseed oil and methanol (closed squares), rapeseed oil, 18\% oleic acid and methanol (closed triangles), and Jatropha oil and methanol with nonimmobilized lipase (closed diamonds). Methanol:oil molar ratio, 3:1; water content, 0.6\% (w/w). 


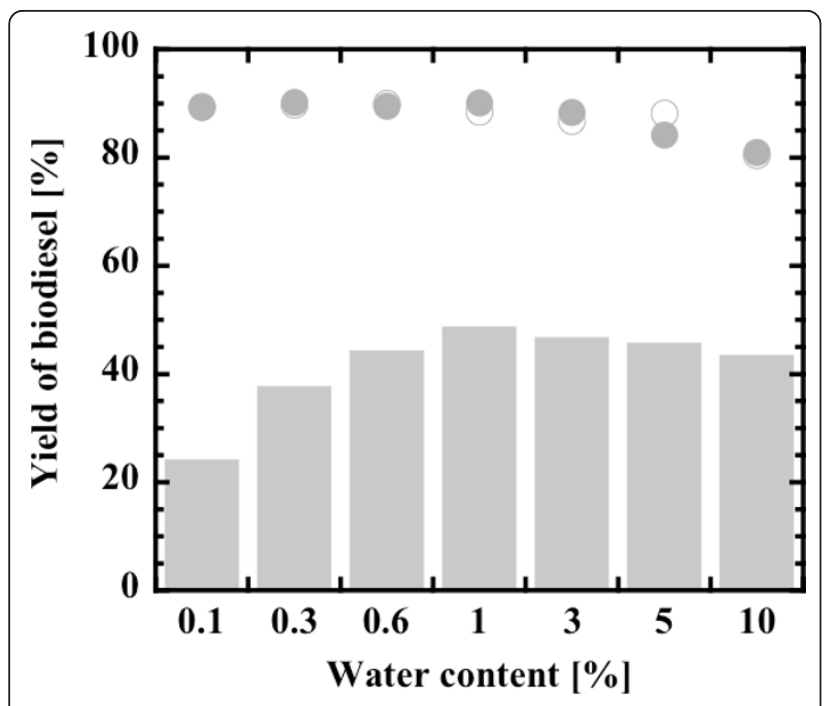

Figure 2 Effect of water content on biodiesel yield. After 0.5 hours (closed gray bars), after 12 hours (open circles) and after 24 hours (closed gray circles). Methanol:oil molar ratio, 3:1.

Gupta [9] reported that $0.7 \%(\mathrm{v} / \mathrm{v})$ was optimum in the ethanolysis of Jatropha oil by immobilized $B$. cepacia lipase. In this study, a water content of $0.6 \%$ was applied in subsequent experiments, because water contents of more than $1 \%(\mathrm{w} / \mathrm{w})$ became insoluble in the initial reaction mixture.

Effect of molar ratio of methanol to oil on biodiesel yield Although the stoichiometric molar ratio of the reaction is $3: 1$, all the lipases are more or less subjected to inhibition and inactivation by alcohols, especially methanol. The optimal molar ratio is therefore dependent on the lipase type. Figure 3 shows the rate of biodiesel production at the different molar ratios of methanol to oil ranging from 1:1 to $6: 1$. The biodiesel production rate was highest at the stoichiometric molar ratio of $3: 1$ and decreased sharply with a further increase in molar ratio up to 6:1. A detailed investigation revealed that the optimal molar ratio was 3.3 to $3.6: 1$, as described in later section.

A three-step separate addition of methanol was attempted at 0 hours, 0.5 hours and 1 hour, to investigate the extent of lipase inactivation by methanol. No significant difference was observed from the one-step whole addition at the start of reaction (data not shown). This agrees with the result reported by Shah and Gupta [9] that $B$. cepacia lipase has much greater resistance to methanol as compared with other lipases.

\section{Effect of glycerol on the production of biodiesel}

Glycerol, a by-product of alcoholysis, is physically adsorbed on the surface of immobilized lipase, retards the

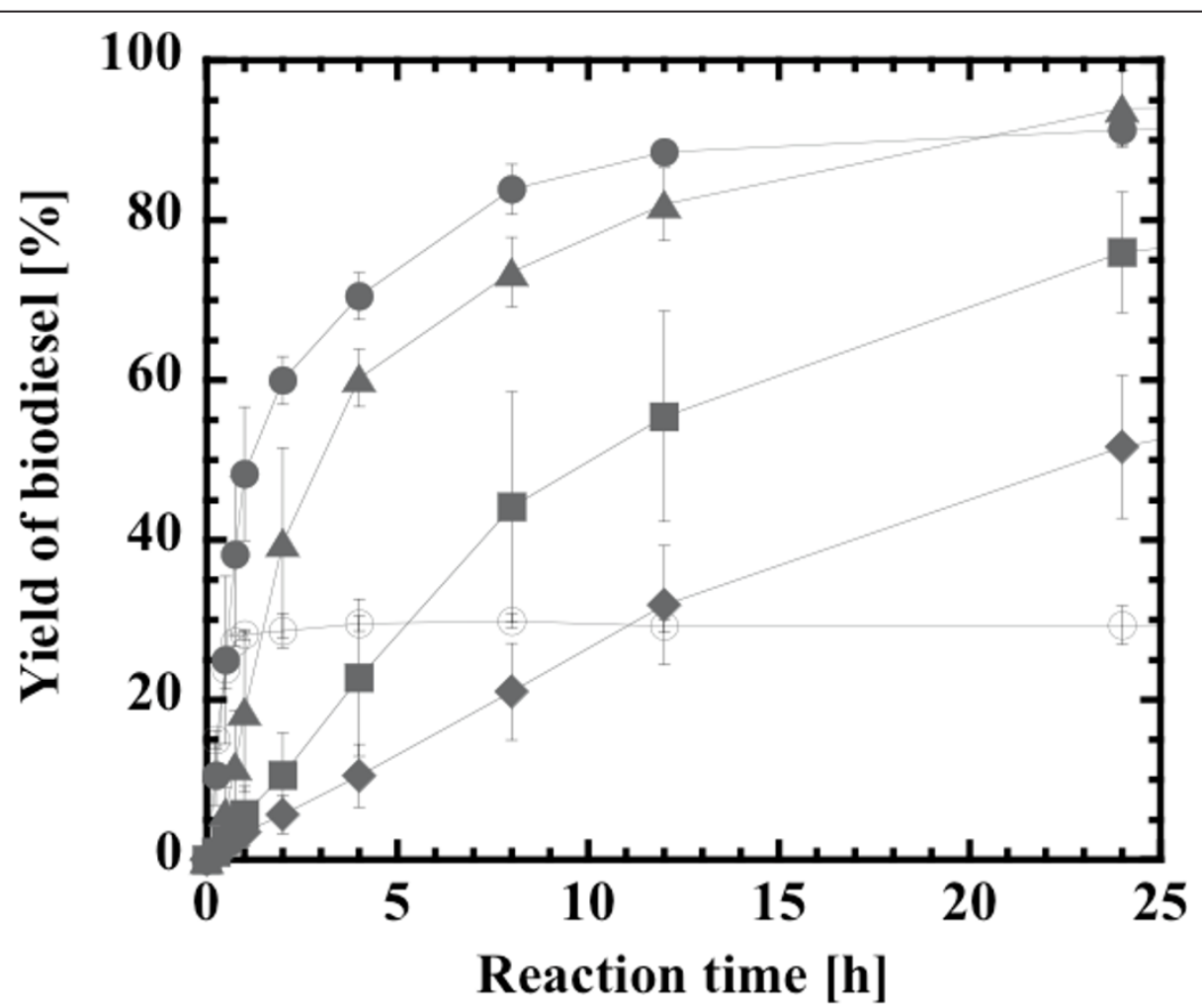

Figure 3 Effect of methanol:oil molar ratio on the production rate of biodiesel. 1:1 (open circles), 3:1 (closed circles), 4:1 (closed triangles), 5:1 (closed squares), and 6:1 (closed diamonds). Water content, 0.6\% (w/w). 
mass transfer of oil to lipase active sites and accordingly lowers the rate of biodiesel production. In the present system involving the stoichiometric mixture of methanol and oil, $10 \%(\mathrm{w} / \mathrm{w})$ glycerol is formed on the basis of the total mass of reaction mixture, when the reaction is completed. The effect of the external addition of glycerol up to $10 \%$ $(\mathrm{w} / \mathrm{w})$ was investigated. As a result, the initial production rate of biodiesel was decreased by approximately $30 \%$ with increasing glycerol concentration up to $10 \%(\mathrm{w} / \mathrm{w})$, as compared with no addition of glycerol (data not shown). ter-Butanol can solubilize glycerol, and is often used as a solvent in lipase-catalyzed biodiesel production [18,26,34-38]. The immobilized lipase used for the 24 hour reaction was washed with ter-butanol or acetone and reused in the second cycle of the same reaction. Figure 4 compares the rate of biodiesel production by the fresh catalyst in the first cycle and non-washed and washed catalysts in the second cycle. Although the initial activity of the non-washed catalyst in the second cycle decreased by $20 \%$ compared with that of the fresh catalyst, that of the washed catalyst was restored by $60 \%$ compared with that of the fresh catalyst. It was, however, apparent that the biodiesel yields after a 24 hour reaction time converged within the range of $85 \%$ to $90 \%$.

\section{Effect of addition of silica gel on the biodiesel yield}

A maximum yield of $90 \%$ was attained after 12 hours at the stoichiometric molar ratio of 3:1. Stevenson et al. [57] reported that the final yield of biodiesel could be further increased by adding silica gel, which may adsorb the glycerol more strongly than the immobilized lipase particles. It has also been reported that the silica gel adsorbs the methanol and its addition is effective for designing a prolonged release system for methanol [58]. The effect of silica gel addition on biodiesel yield was thus investigated for the molar ratio of methanol to oil. The effect of the latter was examined again within the narrow range of molar ratios between $3: 1$ and 3.5:1. The amount of silica gel added was determined to be 1.25 and 1.5 weight equivalents compared with the amount of glycerol produced when the 3:1 stoichiometric mixture was completely reacted. As shown in Figure 5, the results were rather complex. The biodiesel yields after 0.5 hours tended to be slightly increased with an increase in silica gel at the three molar ratio levels, although they differed in extent. No significant effect of molar ratio was observed on the biodiesel yields after 0.5 hours. These results probably mean that part of the glycerol produced was favorably removed from the surface of the immobilized lipase, but methanol

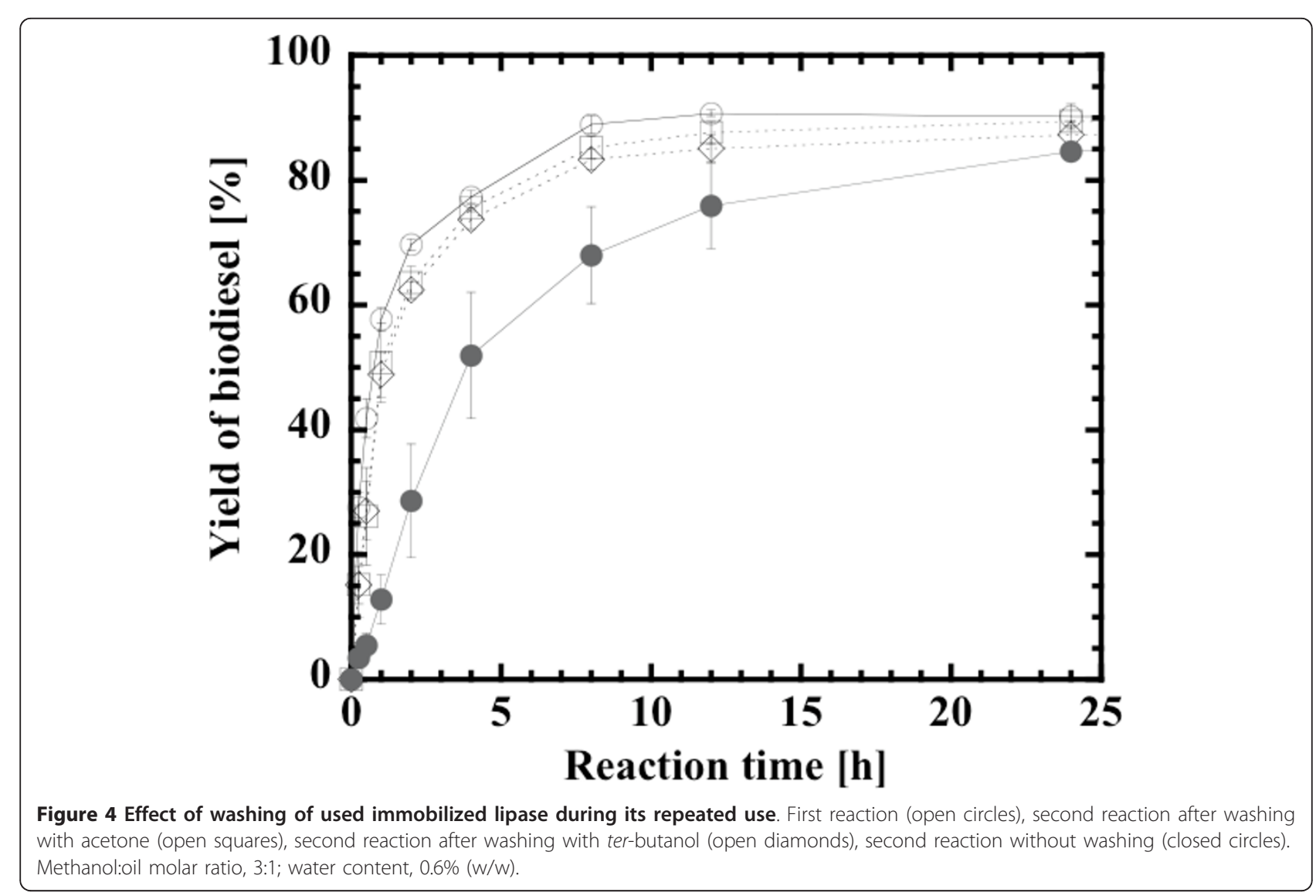






Figure 5 Effect of the addition of silica gel on biodiesel yield. After 0.5 hours (closed gray bars), after 12 hours (open circles) and after 24 hours (closed gray circles). Methanol:oil molar ratio, (a) 3:1; (b) 3.3:1; and (c) 3.5:1. Water content, 0.6\% (w/w).

inhibition was of minor influence. The final biodiesel yields after 12 hours and 24 hours were also slightly increased by the addition of silica gel at molar ratios of 3:1 and 3.3:1, whereas they were unchanged at a molar ratio of $3.5: 1$ giving the highest yield of approximately $95 \%$. It is also noteworthy that the final biodiesel yields were increased up to $95 \%$ at the maximum with an increase in molar ratio of 3:1 to 3.5:1. A possible explanation for the latter may be that a small loss of methanol by vaporization and/or strong distribution into a separated glycerol phase was compensated for by the slight increase in the initial amount of methanol.
Application of a lipase-immobilized silica monolith bioreactor to the continuous production of biodiesel

Silica monolith columns are characterized by mechanical durability of the support and low backpressure of the substrate solution flowing through a macroporous structured support, as compared with conventional packed beds. A lipase-immobilized silica monolith bioreactor was applied to the continuous production of biodiesel from crude Jatropha oil. Figure 6 shows a schematic representation of the bioreactor system used for flowthrough reaction experiments. The stock solution comprised a 3:1 stoichiometric mixture of methanol and oil

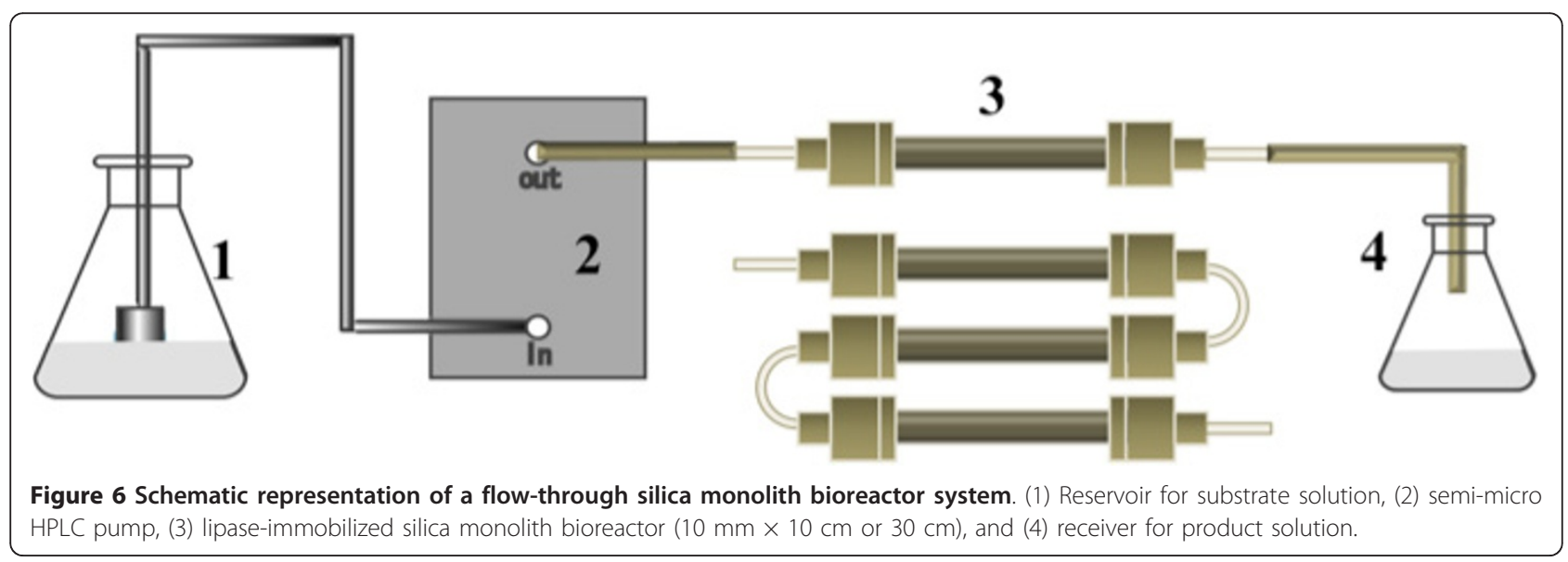


and $0.6 \%(\mathrm{w} / \mathrm{w})$ water. The molar composition of 3:1 was selected for comparison with the majority of the experimental data collected using a non-steady state batchwise reactor. The three lipase-immobilized silica monolith columns (10 $\mathrm{mm}$ inside diameter, $10 \mathrm{~cm}$ length) were connected in series and the substrate solution was allowed to pass through the resultant bioreactor at a volumetric flow rate of $0.6 \mathrm{~mL} / \mathrm{h}$ to $30 \mathrm{~mL} / \mathrm{h}$. Figure 7 shows the relation between the biodiesel yield and time variable, $W / v$ (mass of lipase present in the bioreactor divided by the volumetric flow rate of substrate solution) under steady state operation. If the substrate solution flows through the bioreactor in ideal plug flow, the time variable is equivalent to $m t / V$ (product of the liquid volume based-mass concentration of lipase and reaction time) in a batch slurry reactor $[21,53,54]$. The reaction time, $t$, calculated from the equation:

$$
t=W V / m v
$$

is given on the upper horizontal axis of Figure 7. The continuous monolith bioreactor exhibited lowered biodiesel yields, as compared with the batchwise slurry reactor (Figures 1, 3 and 5). In previous studies on lipasecatalyzed transesterifications in organic solvents, the performance of the continuous silica monolith

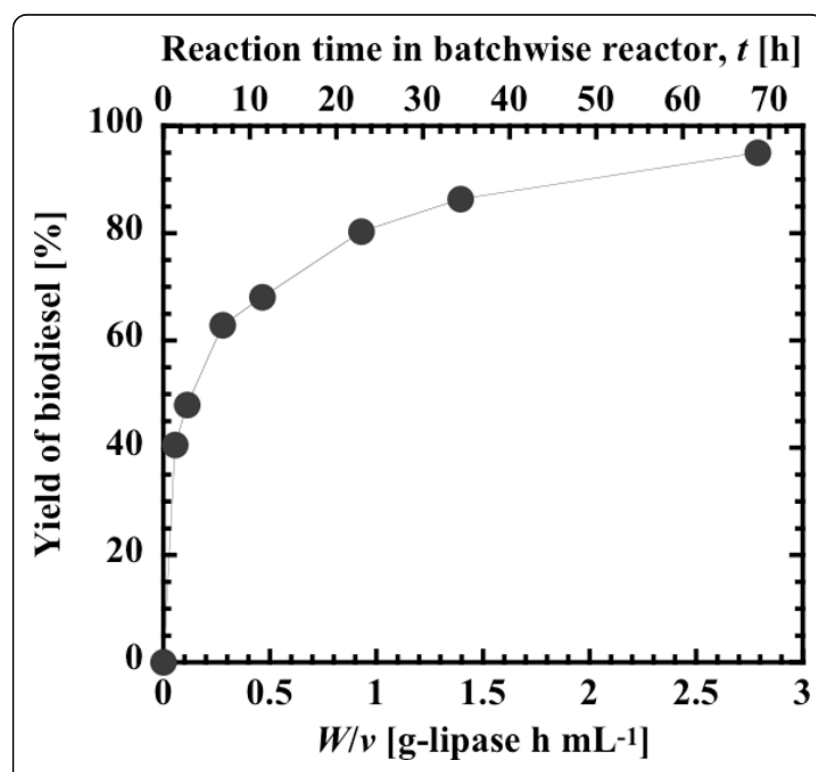

Figure 7 Steady state yields of biodiesel in the lipaseimmobilized silica monolith bioreactor. The yields are shown as a function of W/V (mass of lipase divided by flow rate of substrate solution). The substrate solution, composed of methanol and oil at 3:1 molar ratio and $0.6 \%(\mathrm{w} / \mathrm{w})$ water, was fed continuously at constant flow rates between $0.6 \mathrm{~mL} / \mathrm{h}$ and $30 \mathrm{~mL} / \mathrm{h}$ to the bioreactor $(10 \mathrm{~mm} \times 30 \mathrm{~cm})$ loaded with $4.92 \mathrm{~g}$ silica monolith containing $1.67 \mathrm{~g}$ lipase. microbioreactor was superior to that of the batchwise slurry reactor in terms of conversions at the same values of the time variables, $W / v$ and $m t / V[53,54]$. The decrease in yield in the present biodiesel production system may be a result of the high viscosity of the substrate solution that prevents a uniform forced flow through interparticle spaces within the monolith. Another reason may be steady state adsorption of glycerol on the surface, of which amount may be larger than that in a non-steady state batch reaction. However, the biodiesel yield at steady state under the conditions of lowest volumetric flow rate $(0.6 \mathrm{~mL} / \mathrm{h}, \mathrm{W} / \nu=2.79 \mathrm{~g}$-lipase $\mathrm{h} / \mathrm{mL})$ reached 95\%.

As shown in Figure 8, the operational stability of the lipase-immobilized silica monolith bioreactor was tested by a continuous flow of the substrate solution for a longer period of time at a fixed $W / v$ value of 1.05 g-lipase $\mathrm{h} / \mathrm{mL}$. Although the biodiesel yield gradually decreased from $73 \%$ to $58 \%$ after 49 days of operation, $80 \%$ of the initial yield was retained even after continuous operation for almost 50 days. Washing of the monolith was attempted by replacing the substrate solution with terbutanol during the operation. However, the steady state biodiesel yield after washing was not returned to the initial yield, giving the same yield as that right before washing. It is therefore probable that a gradual decrease in yield resulted from slow inactivation of the lipase by methanol.

\section{Conclusions}

An $n$-butyl-substituted silica monolith that immobilized B. cepacia lipase was applied successfully to the production of biodiesel through the methanolysis of crude Jatropha oil containing $18 \%$ free fatty acid. A biodiesel yield of $90 \%$ was reached in a 12 hour batch reaction using a stoichiometric mixture of methanol and oil (3:1), with a water content of $0.6 \%(\mathrm{w} / \mathrm{w})$ and at a temperature of $40^{\circ} \mathrm{C}$. The continuous production of biodiesel was also achieved using a lipase-immobilized silica monolith bioreactor. The steady state yield of $95 \%$ was attained at the low flow rate of $0.6 \mathrm{~mL} / \mathrm{h}(2.79 \mathrm{~g}$-lipase $\mathrm{h} / \mathrm{mL})$ and $80 \%$ of the initial yield was retained even after continuous operation for almost 50 days.

\section{Methods \\ Materials}

Lipase PS-SD from B. cepacia was purchased from Amano Enzyme Inc. (Nagoya, Japan), and was used without further purification. Jatropha oil used was a kind gift from the Hak plantation, Banteay Meanchey, Cambodia. The fatty acid composition of this oil is shown in Table 1. Rapeseed oil was obtained from Riken Nosan-Kako Co. (Fukuoka, Japan). The composition of fatty acids in this triglyceride was reported by the manufacturer to be 


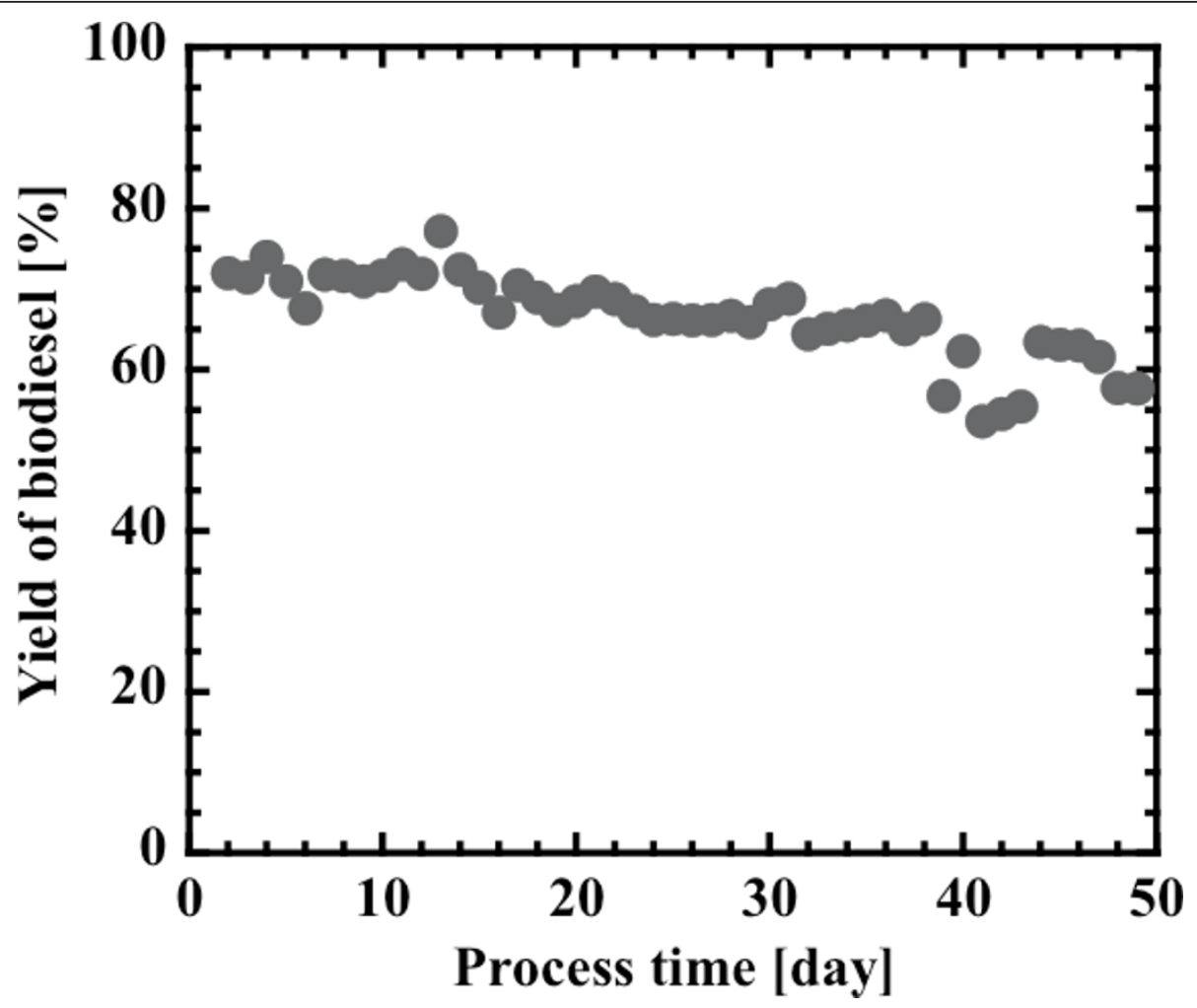

Figure 8 Operational stability of the lipase-immobilized silica monolith bioreactor in the continuous production of biodiesel. The substrate solution, composed of methanol and oil at 3:1 molar ratio and $0.6 \%(\mathrm{w} / \mathrm{w})$ water, was fed continuously at a constant flow rate of 0.06 $\mathrm{mL} / \mathrm{h}$ to the bioreactor $(10 \mathrm{~mm} \times 10 \mathrm{~cm})$ loaded with $1.87 \mathrm{~g}$ silica monolith containing $0.63 \mathrm{~g}$ lipase.

4.2\% palmitic acid, $61.6 \%$ oleic acid, $19.6 \%$ linoleic acid and $10.1 \%$ linolenic acid. The methyl esters of the major fatty acids were obtained from Sigma Aldrich Japan Co. (Tokyo, Japan) and used to construct calibration curves via gas chromatography. TMOS, MTMS and other chemicals were of reagent grade and were purchased from Tokyo Chemical Industries Co. (Tokyo, Japan). $n$-butyltrimethoxysilane (BTMS) was kindly supplied by Dow Corning Toray Co. (Ichihara, Japan).

Preparation of a silica monolith derived from a mixture of MTMS and TMOS

A silica monolith was first prepared using the sol-gel method reported previously [52-54]. At room temperature, a mixture of $3.44 \mathrm{~mL}$ MTMS and $890 \mu \mathrm{L}$ TMOS (molar ratio of MTMS to TMOS, 4:1), $1.05 \mathrm{~mL}$ distilled water and $45 \mu \mathrm{L}$ of $40 \mathrm{mM}$ hydrogen chloride were added consecutively to a test tube. After stirring at room temperature for 10 minutes, the homogeneous sol obtained was cooled to $4^{\circ} \mathrm{C}$ and $9.85 \mathrm{~mL}$ of $100 \mathrm{mM}$ phosphate buffer solution ( $\mathrm{pH}$ 7.5) was added. The molar ratio of silanes to water was 5:100 in this preparation. Gelation was allowed to proceed for 1 day in a container maintained at $23^{\circ} \mathrm{C}$. The resulting hydrogel was lyophilized for 1 day. This produced a non-shrinkable MTMS-based silica monolith in a test tube that was then used as a support for immobilization of lipase.

\section{Preparation of a lipase-immobilized silica monolith coated with butyl-substituted silicates}

A $12 \mathrm{~mL}$ sol solution comprising a mixture of BTMS and TMOS at a fixed molar ratio of 4:1 was prepared in the presence of lipase using the procedure described above. Homogeneous sol in an amount of $0.8 \mathrm{~mL}$ was mixed with $7.2 \mathrm{~mL}$ of $100 \mathrm{mM}$ phosphate buffer solution ( $\mathrm{pH} 7.5)$, and $4 \mathrm{~mL}$ of lipase solution ( $\mathrm{pH} 7.5$ ) was then added. A sol mixture containing $1.2 \mathrm{~g}$ lipase was slowly poured into the MTMS-based silica monolith formed in the test tube. The liquid-solid mixture was degassed under reduced pressure for 10 minutes to permeate the sol solution into the interstices of the monolith. Gelation was allowed to proceed for 1 day in a container maintained at $23^{\circ} \mathrm{C}$. The lipase-immobilized silica monolith, coated with butyl-substituted silicates, was lyophilized for 1 day, then collected and crushed in a mortar. Typically, particles of $0.74 \mathrm{~g}$ crushed silica monolith containing $250 \mathrm{mg}$ lipase were used for batch reaction experiments. 


\section{Preparation of a lipase-immobilized silica monolith bioreactor}

A 10-cm-long glass tube with inside diameter of $10 \mathrm{~mm}$ was used for making a lipase-immobilized silica monolith bioreactor. The glass tube was placed into a test tube and filled with the sol mixture containing MTMS and TMOS, as described above, resulting in the formation of an MTMS-based silica monolith in both the test tube and in the glass tube. In the second step sol-gel coating, the sol mixture of BTMS and TMOS containing $1.2 \mathrm{~g}$ of lipase was poured into the MTMS-based silica monolith formed in the test tube, in which the silica monolith-containing glass tube was still embedded. After a series of treatments as described above, the glass tube was retrieved, and the mass of gel inside and outside the glass tube was measured. The mass of the lipase immobilized within the glass tube was calculated by assuming a uniform distribution throughout the gel. The $10 \mathrm{~mm} \times 10 \mathrm{~cm}$ glass tube was used as the lipase-immobilized silica monolith bioreactor. The three units prepared simultaneously in separate test tubes were connected in series, and the resultant $30-\mathrm{cm}$ long bioreactor was also used for flow-through reaction experiments (Figure 6).

\section{Batch reaction experiments}

The molar ratio of methanol to Jatropha oil is an important variable in the biodiesel production. The Jatropha oil used contained $18 \%$ free fatty acids of which composition was the same as that of total fatty acids in oil. In this study, the molar ratio of methanol to oil was determined based on the molar amount of triglyceride that was supposed to be originally present in the feedstock. Therefore the 3:1 molar mixture meant an equimolar mixture of methanol and total fatty acids contained in the feedstock.

A typical reaction mixture was prepared by mixing $5 \mathrm{~g}$ Jatropha oil and $0.54 \mathrm{~g}$ methanol (molar ratio of methanol to oil, $3: 1$; and water content, $0.6 \%(\mathrm{w} / \mathrm{w})$ based on the total mass) in $20 \mathrm{~mL}$ screw-capped vials. The mixture was stirred at $1400 \mathrm{~min}^{-1}$ on a shaking incubator maintained at $40^{\circ} \mathrm{C}$. The reaction was initiated by the addition of $250 \mathrm{mg}$ lipase powder or $0.74 \mathrm{~g}$ particles of crushed silica monolith containing $250 \mathrm{mg}$ crude, immobilized lipase. Major variables investigated were feedstock type, the molar ratio of methanol to oil $(1: 1$ to $6: 1)$ and the water content $(0.1 \%$ to $10 \%(\mathrm{w} / \mathrm{w}))$. Reactions were carried out in triplicate. Almost all the data were represented as mean \pm standard deviation.

\section{Flow-through reaction experiments}

The glass tubes loaded with lipase-immobilized silica monolith were provided with end fittings, attached to a semi-micro HPLC pump (PU610, GL Sciences Co. (Tokyo, Japan)) and immersed in a constant temperature bath maintained at $40^{\circ} \mathrm{C}$. The substrate solution was fed at volumetric flow rates of $0.6 \mathrm{~mL} / \mathrm{h}$ to $30 \mathrm{~mL} / \mathrm{h}$ using the HPLC pump. Steady state at each flow rate was confirmed when the exit concentration of the fatty acid methyl esters became independent of the process time.

\section{Long-term operational stability test}

The silica monolith bioreactor loaded with $1.87 \mathrm{~g}$ silica monolith, containing $0.63 \mathrm{~g}$ of immobilized lipase, was operated continuously for 49 days. A 3:1 mixture of methanol to oil containing $0.6 \%(\mathrm{w} / \mathrm{w})$ water was fed to the inlet of the bioreactor at a constant volumetric flow rate of $0.06 \mathrm{~mL} / \mathrm{h}$.

\section{Sample analysis}

Organic samples were analyzed using a gas chromatograph (GC-14 B, Shimadzu Co. (Kyoto, Japan)) equipped with a low polarity capillary column DB-5 $(15 \mathrm{~m} \times 0.25 \mathrm{~mm}$ inner diameter and $0.5 \mu \mathrm{m}$ film thickness: Agilent Technologies (Santa Clara, California, USA)). The column oven temperature was initially held at $150^{\circ} \mathrm{C}$ for 0.5 minutes, then raised to $300^{\circ} \mathrm{C}$ at a heating rate of $20^{\circ} \mathrm{C} / \mathrm{min}$, and finally kept at $300^{\circ} \mathrm{C}$ for 3 minutes. The carrier gas was nitrogen with a flow rate of $1 \mathrm{~mL} / \mathrm{min}$. The injector temperature was maintained at $295^{\circ} \mathrm{C}$ and detection was conducted with a flame ionization detecotor maintained at $300^{\circ} \mathrm{C}$. Concentrations of the four fatty acid methyl esters (methyl palmitate, methyl stearate, methyl oleate and methyl linoleate) were quantified using calibration curves prepared by analyzing standard solutions of mixed methyl esters. The biodiesel yield was determined as a ratio of the total concentration of these four methyl esters to the total concentration of corresponding fatty acids in the initial reaction mixture.

\section{Acknowledgements}

This work was supported by Grants-in-Aids for scientific research (No. 22560772) from the Ministry of Education, Culture, Sports, Science and Technology of Japan, and for the feasibility study (A-STEP) from Japan Science and Technology Agency.

\section{Authors' contributions}

KK proposed and directed the research. YO and RT conducted the experiments. KK, YO and RT discussed the results. YO compiled an early draft and KK wrote the paper. All authors read and approved the final manuscript.

Competing interests

The authors declare that they have no competing interests.

Received: 18 June 2011 Accepted: 21 October 2011

Published: 21 October 2011

\section{References}

1. Fukuda $\mathrm{H}$, Kondo A, Noda H: Biodiesel fuel production by transesterification of oils. J Biosci Bioeng 2001, 92:405-416.

2. Akoh CC, Chang SW, Lee GC, Shaw JF: Enzymatic approach to biodiesel production. J Agric Food Chem 2007, 55:8995-9005.

3. Ranganathan SV, Narasimhan SL, Muthukumar K: An overview of enzymatic production of biodiesel. Bioresour Technol 2008, 99:3975-3981. 
4. Fjerbaek L, Christensen KV, Norddahl B: A review of the current state of biodiesel production using enzymatic transesterification. Biotechnol Bioeng 2009, 102:1298-1315.

5. Azocar L, Ciudad G, Heipieper HJ, Navia R: Biotechnological processes for biodiesel production using alternative oils. Appl Microbiol Biotechnol 2010, 88:621-636.

6. Du W, Li W, Sun T, Chen X, Liu D: Perspectives for biotechnological production of biodiesel and impacts. Appl Microbiol Biotechnol 2008, 79:331-337.

7. Antczak MS, Kubiak A, Antczak T, Bielecki S: Enzymatic biodiesel synthesis key factors affecting efficiency of the process. Renewable Energy 2009, 34:1185-1194.

8. Tan T, Lu J, Nie K, Deng L, Wang F: Biodiesel production with immobilized lipase: a review. Biotechnol Adv 2010, 28:628-634.

9. Shah S, Gupta MN: Lipase catalyzed preparation of biodiesel from Jatropha oil in a solvent free system. Process Biochem 2007, 42:409-414

10. Tamalampudi S, Talukder MR, Hama S, Numata T, Kondo A, Fukuda H: Enzymatic production of biodiesel from Jatropha oil: A comparative study of immobilized-whole cell and commercial lipases as a biocatalyst. Biochem Eng J 2008, 39:185-189.

11. Kumari A, Mahapatra P, Garlapati VK, Banerjee R: Enzymatic transesterification of Jatropha oil. Biotechnol Biofuels 2009, 2:1.

12. Nazir N, Ramli N, Mangunwidjaja D, Hambali E, Setyaningsih D, Yuliani S, Yarmo MA, Salimon J: Extraction, transesterification and process control in biodiesel production from Jatropha curcas. Eur J Lipid Sci Technol 2009, 111:1185-1200

13. Abdulla R, Chan ES, Ravindra P: Biodiesel production from Jatropha curcas: a critical review. Crit Rev Biotechnol 2011, 31:53-64.

14. Dossat V, Combes D, Marty A: Continuous enzymatic transesterification of high oleic sunflower oil in a packed bed reactor: influence of the glycerol production. Enzyme Microb Technol 1999, 25:194-200.

15. Watanabe $Y$, Shimada $Y$, Sugihara A, Tominaga Y: Enzymatic conversion of waste edible oil to biodiesel fuel in a fixed-bed bioreactor. J Am Oil Chem Soc 2001, 78:703-707.

16. Hsu AF, Jones KC, Foglia TA, Marmer WN: Continuous production of ethyl esters of grease using an immobilized lipase. J Am Oil Chem Soc 2004, 81:749-752.

17. Nie K, Xie F, Wang F, Tan T: Lipase catalyzed methanolysis to produce biodiesel: optimization of the biodiesel production. J Mol Catal B Enzym 2006, 43:142-147.

18. Royon D, Daz M, Ellenrieder G, Locatelli S: Enzymatic production of biodiesel from cotton seed oil using $t$-butanol as a solvent. Bioresour Technol 2007, 98:648-653.

19. Halim SFA, Kamaruddin AH, Fernando WJN: Continuous biosynthesis of biodiesel from waste cooking palm oil in a packed bed reactor: optimization using response surface methodology and mass transfer studies. Bioresour Technol 2009, 100:710-716.

20. Jachmanian I, Dobroyan M, Moltini M, Segura N, Irigaray B, Veira JP, Vieitez I, Grompone MA: Continuous lipase-catalyzed alcoholysis of sunflower oil: effect of phase-equilibrium on process efficiency. J Am Oil Chem Soc 2010, 87:45-53

21. Severac E, Galy O, Turon F, Pantel CA, Condoret JS, Monsan P, Marty A: Selection of CalB immobilization method to be used in continuous oil transesterification: analysis of the economical impact. Enzyme Microb Technol 2011, 48:61-70

22. Shimada Y, Watanabe $Y$, Samukawa T, Sugihara A, Noda H, Fukuda H, Tominaga Y: Conversion of vegetable oil to biodiesel using immobilized Candida antarctica lipase. J Am Oil Chem Soc 1999, 76:789-793.

23. $\mathrm{Xu}$ Y, Du W, Liu D, Zeng J: A novel enzymatic route for biodiesel production from renewable oils in a solvent-free medium. Biotechnol Lett 2003, 25:1239-1241.

24. Deng L, Xu X, Haraldsson GG, Tan T, Wang F: Enzymatic production of alkyl esters through alcoholysis: A critical evaluation of lipases and alcohols. J Am Oil Chem Soc 2005, 82:341-347.

25. Chen JW, Wu WT: Regeneration of immobilized Candida antarctica lipase for transesterification. J Biosci Bioeng 2003, 95:466-469.

26. Li W, Du W, Liu D, Yao Y: Study on factors influencing stability of whole cell during biodiesel production in solvent-free and tert-butanol system. Biochem Eng J 2008, 41:111-115.

27. Iso $M$, Chen $B$, Eguchi M, Kubo T, Shrestha S: Production of biodiesel fuel from triglycerides and alcohol using immobilized lipase. J Mol Catal B Enzym 2001, 16:53-58.
28. Hsu AF, Jones K, Foglia TA, Marmer WN: Immobilized lipase-catalyzed production of alkyl esters of restaurant grease as biodiesel. Biotechnol Appl Biochem 2002, 36:181-186.

29. Salis A, Pinna M, Monduzzi M, Solinas V: Biodiesel production from triolein and short chain alcohols through biocatalysis. J Biotechnol 2005, 119:291-299.

30. Hsu AF, Jones K, Marmer WN, Foglia TA: Production of alkyl esters from tallow and grease using lipase immobilized in a phyllosilicate sol-gel. J Am Oil Chem Soc 2001, 78:585-588.

31. Du W, Xu Y, Liu D, Zeng J: Comparative study on lipase-catalyzed transformation of soybean oil for biodiesel production with different acyl acceptors. J Mol Catal B Enzym 2004, 30:125-129.

32. Orcaire O, Buisson P, Pierre AC: Application of silica aerogel encapsulated lipases in the synthesis of biodiesel by transesterification reactions. $J \mathrm{Mo}$ Catal B Enzym 2006, 42:106-113.

33. Modi MK, Reddy JRC, Rao BVSK, Prasad RBN: Lipase-mediated conversion of vegetable oils into biodiesel using ethyl acetate as acyl acceptor. Bioresour Technol 2007, 98:1260-1264.

34. Li L, Du W, Liu D, Wang L, Li Z: Lipase-catalyzed transesterification of rapeseed oils for biodiesel production with a novel organic solvent as the reaction medium. J Mol Catal B Enzym 2006, 43:58-62.

35. Du W, Liu D, Li L, Dai L: Mechanism exploration during lipase-mediated methanolysis of renewable oils for biodiesel production in a tert-butanol system. Biotechnol Prog 2007, 23:1087-1090.

36. Su E, Wei D: Improvement in lipase-catalyzed methanolysis of triacylglycerols for biodiesel production using a solvent engineering method. J Mol Catal B Enzym 2008, 55:118-125.

37. Halim SFA, Kamaruddin AH: Catalytic studies of lipase on FAME production from waste cooking palm oil in a ter-butanol system. Process Biochem 2008, 43:1436-1439.

38. Zheng Y, Quan J, Ning X, Zhu LM, Jiang B, He ZY: Lipase-catalyzed transesterification of soybean oil for biodiesel production in tert-amyl alcohol. World J Microbiol Biotechnol 2009, 25:41-46.

39. Kaieda M, Samukawa T, Kondo A, Fukuda H: Effect of methanol and water contents on production of biodiesel fuel from plant oil catalyzed by various lipases in a solvent-free system. J Biosci Bioeng 2001, 91:12-15.

40. Soumanou MM, Bornscheuer UT: Improvement in lipase-catalyzed synthesis of fatty acid methyl esters from sunflower oil. Enzyme Microb Technol 2003, 33:97-103.

41. Noureddini H, Gao X, Philkana RS: Immobilized Pseudomonas cepacia lipase for biodiesel fuel production from soybean oil. Bioresour Technol 2005, 96:769-777.

42. Kumari V, Shah S, Gupta MN: Preparation of biodiesel by lipase-catalyzed transesterification of high free fatty acid containing oil from Madhuca indica. Energy Fuel 2007, 21:368-372.

43. Moreira ABR, Perez VH, Zanin GM, de Castro HF: Biodiesel synthesis by enzymatic transesterification of palm oil with ethanol using lipases from several sources immobilized on silica-PVA composite. Energy Fuel 2007, 21:3689-3694.

44. Salis A, Pinna M, Monduzzi M, Solinas V: Comparison among immobilized lipases on macroporous polypropylene toward biodiesel synthesis. $\mathrm{J} \mathrm{Mol}$ Catal B Enzym 2008, 54:19-26.

45. Salis A, Bhattacharyya MS, Monduzzi M, Solinas V: Role of the support surface on the loading and the activity of Pseudomonas fluorescens lipase used for biodiesel synthesis. J Mol Catal B Enzym 2009, 57:262-269.

46. Da Ros PCM, Silva GAM, Mendes AA, Santos JC, de Castro HF: Evaluation of the catalytic properties of Burkholderia cepacia lipase immobilized on non-commercial matrices to be used in biodiesel synthesis from different feedstocks. Bioresour Technol 2010, 101:5508-5515.

47. Kawakami K, Yoshida S: Thermal stabilization of lipase by sol-gel entrapment in organically modified silicates formed on kieselguhr. $J$ Ferment Bioeng 1996, 82:239-245.

48. Reetz MT: Entrapment of biocatalysts in hydrophobic sol-gel materials for use in organic chemistry. Adv Mater 1997, 9:943-954.

49. Furukawa S, Ono T, ljima H, Kawakami K: Effect of imprinting sol-gel immobilized lipase with chiral template substrates in esterification of (R)-(+)- and (S)-(-)-glycidol. J Mol Catal B Enzym 2002, 17:23-28.

50. Reetz MT, Tielmann P, Wiesenfofer W, Konen W, Zonta A: Second generation sol-gel encapsulated lipases: robust heterogeneous biocatalysts. Adv Synth Catal 2003, 345:717-728. 
51. Chen JP, Lin WS: Sol-gel powders and supported sol-gel polymers for immobilization of lipase in ester synthesis. Enzyme Microb Technol 2003, 32:801-811.

52. Kawakami K, Sera Y, Sakai S, Ono T, ljima H: Development and characterization of a silica monolith immobilized enzyme microbioreactor. Ind Eng Chem Res 2005, 44:236-240.

53. Kawakami K, Abe D, Kawashima A, Oda Y, Takahashi R, Sakai S: Development of a silica monolith microbioreactor entrapping highly activated lipase and an experiment toward integration with chromatographic separation of chiral esters. J Sep Sci 2007, 30:3077-3084.

54. Kawakami K, Takahashi R, Shakeri M, Sakai S: Application of a lipaseimmobilized silica monolith bioreactor to the production of fatty acid methyl esters. J Mol Catal B Enzym 2009, 57:194-197.

55. Talukder MMR, Wu CJ, Fen NM, Melisa YLS: Two-step lipase catalysis for production of biodiesel. Biochem Eng J 2010, 49:207-212.

56. Meng Y, Wang G, Yang N, Zhou Z, Li Y, Liang X, Chen J, Li Y, Li J: Two-step synthesis of fatty acid ethyl ester from soybean oil catalyzed by Yarrowia lipolytica lipase. Biotechnol Biofuels 2011, 4:6.

57. Stevenson DE, Stanley RA, Furneaux RH: Near-quantitative production of fatty acid alkyl esters by lipase-catalyzed alcoholysis of fats and oils with adsorption of glycerol by silica gel. Enzyme Microb Technol 1994, 16:478-484.

58. Luo Y, Wang G, Ma Y, Wei D: Application of a silica gel prolonged-release system for methanol in the production of biodiesel. J Chem Technol Biotechnol 2006, 81:1846-1848.

doi:10.1186/1754-6834-4-42

Cite this article as: Kawakami et al:. Application of a Burkholderia cepacia lipase-immobilized silica monolith to batch and continuous biodiesel production with a stoichiometric mixture of methanol and crude Jatropha oil. Biotechnology for Biofuels 2011 4:42.

\section{Submit your next manuscript to BioMed Central and take full advantage of:}

- Convenient online submission

- Thorough peer review

- No space constraints or color figure charges

- Immediate publication on acceptance

- Inclusion in PubMed, CAS, Scopus and Google Scholar

- Research which is freely available for redistribution

Submit your manuscript at www.biomedcentral.com/submit 